\title{
Vibration white finger and digital systolic pressure during cooling
}

\author{
LENA EKENVALL AND LE LINDBLAD
}

From the Departments of Occupational Medicine and Clinical Physiology, Södersjukhuset, Stockholm, Sweden

ABSTRACT A cold provocation test (measurement of finger systolic pressure during combined body and local finger cooling) was performed on 111 male patients exposed to vibration and with a typical history of cold induced white finger. A new method of calculating the test result is describednamely, digital systolic blood pressure in the cooled test finger as a percentage of the systolic pressure in the arm (DP\%). The conventional way of calculating the result, the systolic pressure in the cooled test finger as a percentage of the systolic pressure in the test finger when heated to $30^{\circ} \mathrm{C}$, corrected for changes in systemic pressure by the use of a reference finger (FSP\%), requires the measurement of the systolic pressure in a reference finger. The two ways of calculating the test results give a similar sensitivity (74\% for FSP\%, 79\% for DP\% if all histories are regarded as true) but the new method does not require pressure measurements in a reference finger. This makes the test easier to perform and the result easier to understand.

Vibration white finger (VWF) is a disease that, in many countries, entitles the patient to compensation. Thus there is a need for objective verification of the disease even when the history is suggestive. Many tests have been described ${ }^{1-4}$ but none is universally accepted, indicating that the ideal test has not yet been developed. The measurement of finger systolic pressure during general body and local finger cooling is the method that was initially claimed to have both a high sensitivity and specificity..$^{5-7}$ In clinical routine use, however, the test appears to have a lower sensitivity than was reported earlier. The aim of the present study was to evaluate further the test method in a large number of patients with VWF and also to evaluate the conventional way of calculating the result of the test. ${ }^{8}$

\section{Subjects and methods}

All patients at the department of occupational medicine, Södersjukhuset, with suspected VWF were referred for a cold provocation test as described earlier. ${ }^{7}$ The patients rested for 15 minutes in a thermostated room $\left(16 \pm 2^{\circ} \mathrm{C}\right)$ before the measurement. They were not allowed to smoke for four hours before testing.

Immediately after each pressure measurement in

Accepted 5 August 1985 the fingers, blood pressure in the same arm was taken using a sphygmomanometer cuff. No tests were performed during the summer.

During the cold provocation test, the measurements shown in table 1 were made; the table also lists the abbreviations used in the text. Cooling to $10^{\circ} \mathrm{C}$ was done systematically only in patients having a normal $\mathrm{FSP} \%$ at $15^{\circ} \mathrm{C}$. The results at $10^{\circ} \mathrm{C}$ have been included only for those with a normal test result at $15^{\circ} \mathrm{C}$.

FSP $\%$ at $15^{\circ} \mathrm{C}$ and $10^{\circ} \mathrm{C}$ was calculated according to the equation in table $1 .^{8}$ The test result was also calculated as the digital systolic pressure as a percentage of the systolic pressure in the arm (DP\%) at $30^{\circ}, 15^{\circ}$, and $10^{\circ} \mathrm{C}$ (table 1 ).

Two reference groups of healthy subjects were also examined. One group consisted of 14 men who had never worked with vibrating tools (unexposed controls), the other of 15 men who had been exposed to vibration at work for at least five years but who had no symptoms in the hands or arms (exposed controls).

From January 1982 to April 1984136 patients who had been exposed to vibration were examined using the cold provocation test. Twenty five had no distinct history of cold induced white finger and so were not included in the study. The remaining 111 patients with a history of typical Raynaud's phenomenon comprised the final study group. The severity of the 
Table 1 Measurements taken during the cold provocation test, and abbreviations used in the text

Finger systolic pressure in the test finger with water temperature of $30^{\circ} \mathrm{C}, 15^{\circ} \mathrm{C}$, and $10^{\circ} \mathrm{C}$ in the water cuff $\left(\mathrm{P}_{\mathrm{H}_{2} \mathrm{O} 30}, \mathrm{P}_{\mathrm{H}_{2} \mathrm{O}} 15\right.$, and $\mathrm{P}_{\mathrm{H}_{2} \mathrm{O} \text { 10 }}$ )

Finger systolic pressure in the reference finger $\left(P_{\text {ref } 30}, P_{\text {ref } 15}\right.$, and $P_{\text {ref 10 }}$ )

Arm systolic pressure ( $P_{\text {arm 30 }}, P_{\text {arm 15 }}$, and $\left.P_{\text {arm 10 }}\right)$

FSP\% ${ }_{\text {TC }}=\frac{P_{\mathrm{H}_{2} \mathrm{OT}} \times 100}{P_{\mathrm{H}_{2} \mathrm{O} 30}-\left(P_{\text {ref 30 }}-P_{\text {ref } \mathrm{T}}\right)}$

$\mathrm{DP} \%_{\mathrm{TC}}=\frac{\mathrm{P}_{\mathrm{H}_{2} \mathrm{OT}} \times 100}{\mathrm{P}_{\mathrm{arm} \mathrm{T}}}$

where $\mathrm{T}^{\circ} \mathrm{C}$ corresponds to $30^{\circ} \mathrm{C}, 15^{\circ} \mathrm{C}$, or $10^{\circ} \mathrm{C}$

vasospastic disease was graded according to the Taylor-Pelmear symptom scale ${ }^{9}$ in three groups (T1 to T3), where T1, T2, and T3 corresponds to TaylorPelmear groups 1, 2, and 3-4, respectively. Fifteen patients whose test results were normal, when calculated as FSP\%, were re-examined, two on the same day, the others at a later date.

For statistical analysis Mann-Whitney's two sample rank test and Spearman's rank correlation test were used. The Chi squared test was used when comparing the number of pathological test results in the three categories of patients (T1-T3).

\section{Results}

\section{REFERENCE GROUPS}

There were no significant differences between the unexposed and the exposed control groups in the test results calculated as FSP $\%$ at $15^{\circ} \mathrm{C}$ and $10^{\circ} \mathrm{C}$, or as $\mathrm{DP} \%$ at $15^{\circ} \mathrm{C}$ (table 2). The exposed control group, however, had a significantly lower DP\% $\%_{10} \mathrm{c}$ than the unexposed group (p<0.05). FSP $\%$ and DP\% values of $65 \%$ or less were considered pathological at $15^{\circ} \mathrm{C}$ and $60 \%$ or less at $10^{\circ} \mathrm{C}$. With these limits, one of the 29 controls had an abnormal test result expressed as FSP\%, and two were abnormal when the results were expressed as DP\%.

The median change in arm systolic pressure was small between the first measurement with water at $30^{\circ} \mathrm{C}$ in the water cuff and the second at $15^{\circ} \mathrm{C}$

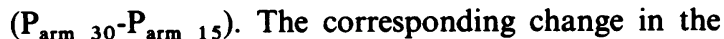
systolic pressure in the reference finger $\left(P_{\text {ref } 30}-P_{\text {ref } 15}\right)$ was also small (table 3 ). There was a significant correlation between the change in the systolic pressures in the arm and the reference finger in the unexposed controls $(r=0.50, p<0.05)$ but not in the exposed controls $(r=0.11, p>0.25)$.

\section{PATIENT GROUPS}

One patient was not tested because the systolic pressure in the test finger was $10 \mathrm{~mm} \mathrm{Hg}$ even after warming to $30^{\circ} \mathrm{C}$. In another patient no blood pressure could be registered in the reference finger at $15^{\circ} \mathrm{C}$. His FSP $\%_{15} \mathrm{C}$ which, when calculated conventionally, would have been $-150 \%$, has been regarded as $0 \%$.

When the test results were expressed as FSP\%, 29 of the 111 patients were within the normal range whereas 23 of the 111 were classified as normal when the results were expressed as DP\%. This corresponds to a sensitivity of $74 \%$ and $79 \%$, respectively. Of the 15 patients retested because their FSP\% was within normal limits at the first examination, 13 had pathological test results on the second occasion. The patients with more advanced disease had a lower median FSP $\%_{15^{\circ} \mathrm{C}}$ and a lower median DP\% $\%_{15^{\circ} \mathrm{C}}$ than those with less advanced disease (fig 1). The frequency of pathological test results calculated as FSP\% and DP\% increased with the severity of the disease ( $p<$ 0.05 ); fig 2 shows a comparison of the two methods used to calculate the test result.

In the patient group the median change in arm systolic pressure was small between the first measurement at $30^{\circ} \mathrm{C}$ and the second at $15^{\circ} \mathrm{C}$ $\left(P_{\text {arm 30}}-P_{\text {arm 15 }}\right)$. Some patients, however, showed a large decrease in systolic pressure in the reference finger (maximum $100 \mathrm{~mm} \mathrm{Hg}$ ) from the first to the second measurement (table 3). As in the exposed controls there was no significant correlation between changes in systolic pressure in the arm and in the reference finger.

There was no significant difference in systolic arm pressure $\left(P_{\text {arm 30 }}\right)$ between the patients and the controls (table 3 ). The finger systolic pressure in the test finger at $30^{\circ} \mathrm{C}$, however, was significantly lower $(\mathrm{p}<$ 0.05 ) in the patient group than in either of the control groups.

Table 2 Results of the cold provocation test in the reference groups. (Medians and (range)s are shown)

\begin{tabular}{|c|c|c|c|c|}
\hline & \multicolumn{2}{|c|}{ Reference group } & \multirow{2}{*}{$\begin{array}{l}\text { Suggested lower normal } \\
\text { limit }\end{array}$} & \multirow[t]{2}{*}{ No with abnormal results } \\
\hline & Unexposed & Exposed & & \\
\hline $\begin{array}{l}\text { No } \\
\text { FSP\% } \%_{15^{\circ} \mathrm{C}} \text { (range) } \\
\text { FSP } \%_{10^{\circ} \mathrm{C} \text { (range) }} \\
\text { DP } \%_{15^{\circ} \mathrm{C} \text { (range) }} \\
\text { DP\% } \%_{10^{\circ} \mathrm{C}} \text { (range) }\end{array}$ & $\begin{array}{l}14 \\
86(67-100) \\
83(59-96) \\
89(67-105) \\
86(61-105)\end{array}$ & $\begin{array}{l}15 \\
92(67-105) \\
77(67-100) \\
83(64-100) \\
80(63-92)\end{array}$ & $\begin{array}{l}65 \\
60 \\
65 \\
60\end{array}$ & $\begin{array}{l}0 \\
1 \\
2 \\
0\end{array}$ \\
\hline
\end{tabular}


Table 3 Data from the cold provocation test in the reference and patient groups. (Medians and (range)s are shown)

\begin{tabular}{llcc}
\hline & Reference group & Patients \\
\cline { 2 - 4 } & Unexposed & Exposed & $120(100$ to 175$)$ \\
\hline$P_{\text {arm 30 }}$ (range) & $120(90$ to 140$)$ & $125(110$ to 140$)$ & $110(10$ to 150$)$ \\
$P_{\mathrm{H}_{2} \mathrm{O} 30}$ (range) & $120(100$ to 145$)$ & $120(100$ to 140$)$ & $0(-15$ to 15$)$ \\
$\mathbf{P}_{\text {arm 30 }}-\mathbf{P}_{\text {arm 15 }}$ (range) & $0(-15$ to 15$)$ & $0(-20$ to 5$)$ & $0(-30$ to 100$)$ \\
$P_{\text {ref 30 }}-P_{\text {ref 15 }}$ (range) & $-5(-20$ to 10$)$ & $0(-15$ to 10$)$ & \\
\hline
\end{tabular}

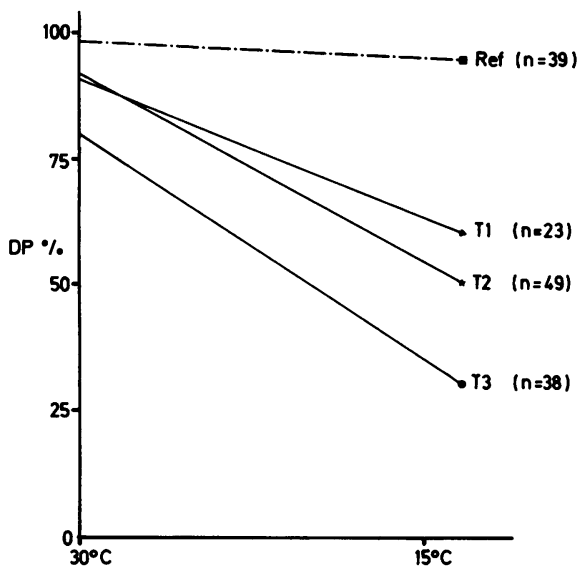

Fig 1 Median $D P \%$ at $30^{\circ} \mathrm{C}$ and $15^{\circ}$ in patients, divided into three subgroups according to their subjective symptoms, and in referents.

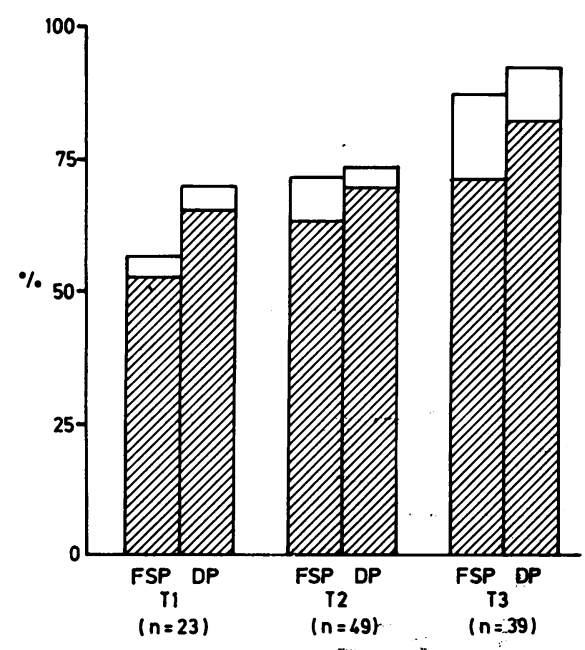

Fig 2 Comparison of calculating test results as FSP\% and $D P \%$ in three patient groups. Percentage pathological tests at $15^{\circ} \mathrm{C}$ (shaded area) and at $10^{\circ} \mathrm{C}$.

\section{Discussion}

The measurement of finger systolic pressure during general body and local finger cooling has been used for some years as a diagnostic tool in VWF. In the present study the sensitivity was not as high as reported earlier. Supposing that all the patients gave a true history of cold induced white finger then approximately $25 \%$ false negative results are obtained with the limits used. When the results are expressed as FSP\%, the sensitivity increased from $57 \%$ in mild to $87 \%$ in advanced disease. Thus one explanation for the higher sensitivity in previous studies may be that the patients had more advanced disease. The patients' smoking habits also influence the result of the test, ${ }^{10}$ nicotine users having more pathological test results than non-users, and differences in nicotine consumption may be another factor that affects the sensitivity. The frequency of pathological test results is the same in a retested subgroup whose tests were initially normal as in the whole group. This indicates that the normal results obtained in the patient group are false negatives and not caused by the patients giving a false history.

In the test described here controls exposed to vibration have a tendency towards lower test results, reaching statistical significance for $\mathrm{DP} \%$ at $10^{\circ} \mathrm{C}$. In an earlier study we examined a healthy exposed control who had an FSP\% ${ }_{15}{ }^{\circ} \mathrm{C}$ of $60 \%{ }^{7}{ }^{7}$ Four years later he developed clinical Raynaud's phenomena; his FSP $\%_{15^{\circ} \mathrm{C}}$ then was $0 \%$. Thus the somewhat exaggerated reaction in the vessels of exposed controls may be a sign of preclinical disease. ${ }^{6}$ The controls in the present study will be followed up after a five year interval to test the hypothesis that low test results are an early sign of VWF.

Patients with VWF and healthy controls exposed to vibration have a prolonged rewarming time after cooling of the hands compared with unexposed controls. ${ }^{11}$ In the present study patients with VWF had a significantly lower systolic pressure in the test finger when heated to $30^{\circ} \mathrm{C}$ than the controls. This is consistent with results previously obtained ${ }^{6}$ and may reflect their prolonged rewarming time. Warming for five minutes with water at $30^{\circ} \mathrm{C}$ in the cuff may not be 
sufficient to release a vasospasm induced by general cooling before the start of the measurements. Another explanation for the low pressure in the warm test finger may be the presence of organic changes in the digital arteries, ${ }^{6}$ earlier shown to be present in some patients by angiographic ${ }^{12}$ or histological ${ }^{13}$ techniques.

Of the 111 patients in this study, 16 with advanced symptoms had their finger systolic pressure measured after vasodilatation (body heating, sometimes combined with alcohol by mouth). Under these circumstances all the patients had a normal systolic finger pressure, indicating that serious organic changes were not present in the digital arteries. The low finger systolic pressure at $30^{\circ} \mathrm{C}$ in patients with VWF thus seems to depend on functional vasospasm rather than on organic lesions.

The formula for calculating FSP\% is based on the pressure in a warm $\left(30^{\circ} \mathrm{C}\right)$ test finger as a reference value for the pressures in the cooled test finger at $15^{\circ}$ and $10^{\circ} \mathrm{C}$. The observation that some patients with VWF have low digital systolic pressure at $30^{\circ} \mathrm{C}$ makes the calculation of the results as FSP\% questionable. Moreover, some patients with VWF have a low systolic pressure in their reference finger during the test procedure, not corresponding to changes in the systemic pressure but presumably induced by a vasospastic reaction on general cooling. In neither patients with VWF nor in vibration exposed controls was there any significant correlation between pressure changes in the reference finger and in the arm. Thus the use of a reference finger to compensate for changes in systemic pressure may be invalid in VWF. The change in systemic pressure when measured in the arm during the cold provocation test is small. If it is regarded as necessary to compensate for this small pressure change it seems better to use the systolic pressure in the arm. With this approach there is no need to measure the pressure in a reference finger at all, making the examination easier to perform and the results easier to understand.

\section{References}

${ }^{1}$ Hellström B, Myhre K. A comparison of some methods of diagnosing Raynaud phenomena of occupational origin. $\mathrm{Br} \mathrm{J}$ Ind Med 1971;28:272-9.

${ }^{2}$ Okada A, Yamashita T, Nagano C, Ikeda T, Yachi A, Shibata S. Studies on the diagnosis and pathogenesis of Raynaud's phenomenon of occupational origin. Br J Ind Med 1971;28:353-7.

${ }^{3}$ Nielsen SL, Lassen N. Measurement of digital blood pressure after local cooling. J Appl Physiol 1977;43:907-10.

${ }^{4}$ Juul C, Nielsen SL. Locally induced digital vasospasm detected by delayed rewarming in Raynaud's phenomenon of occupational origin. Br J Ind Med 1981;38:87-90.

${ }^{5}$ Olsen N, Nielsen SL. Diagnosis of Raynaud's phenomenon in quarrymen's traumatic vasospastic disease. Scand J Work Environ Health 1979;5:249-56.

${ }^{6}$ Olsen N, Nielsen SL, Voss P. Cold response of digital arteries in chain saw operators. Br J Ind Med 1981;38:82-8.

${ }^{7}$ Ekenvall L, Lindblad LE. Digital blood pressure after local cooling as a diagnostic tool in traumatic vasospastic disease. $\mathrm{Br} \mathrm{J}$ Ind Med 1982;39:388-91.

${ }^{8}$ Nielsen SL. Raynaud phenomena and finger systolic pressure during cooling. Scand J Clin Lab Invest 1978;38:765-70.

${ }^{9}$ Taylor W, Pelmear PL, eds. Vibration white finger in industry. London: Academic Press, 1975:xxi.

${ }^{10}$ Ekenvall L, Lindblad LE. Vibrationsutlösta Raynaudfenomen och nikotinkonsumtion-en preliminär rapport. Opuscula Medica 1985;30:28-31.

${ }^{11}$ Ekenvall L, Lindblad LE. Köldprovokationstest vid utredning av traumatisk vasospastisk sjukdom. Opuscula Medica 1979;24: 141-3.

12 James PB, Galloway RW. Arteriography of the hand in men exposed to vibration. In: Taylor W, Pelmear PL, eds. Vibration white finger in industry. London: Academic Press, 1975:31-41.

${ }^{13}$ Ashe WF, Cook WT, Old JW. Raynaud's phenomenon of occupational origin. Arch Environ Health 1962;5:333-43. 